\title{
Rancang Bangun Aplikasi Pengenalan Ukiran Bali dengan Metode ORB
}

\author{
I Gusti Lanang Trisna Sumantara, I Putu Agung Bayupati, Ni Kadek Ayu Wirdiani \\ Jurusan Teknologi Informasi, Fakultas Teknik, Universitas Udayana \\ Bukit Jimbaran, Bali, Indonesia, telp. +6285102853533 \\ e-mail: e-mail: trisnasumantara@gmail.com,bayuhelix@yahoo.com , ayu_wirdi@yahoo.com
}

\begin{abstract}
Abstrak
Ukiran Bali merupakan salah satu seni budaya yang ada di Bali dan memiliki bermacam jenis dalam penerapannya. Informasi yang minim terhadap ukiran Bali mengakibatkan masyarakat kurang mengetahui jenis ukiran Bali. Informasi yang minim tentang ukiran Bali dapat diatasi dengan memanfaatkan kemajuan teknologi informasi dibidang pengolahan citra, yakni untuk membangun aplikasi yang mampu mengenali ukiran Bali. Aplikasi yang dibangun merupakan aplikasi mobile yang dapat digunakan pada smartphone dengan sistem operasi Android. Metode yang diterapkan yakni metode Oriented FAST and Rotated BRIEF (ORB) yang mampu mengenali citra ukiran Bali berdasarkan fitur keypoints. Pencocokan citra ukiran menggunakan metode Bruteforce Hamming Distance untuk menemukan kemiripan antar fitur citra ukiran sehingga mampu dikenali. Hasil akurasi dari penelitian proses pengenalan ukiran Bali dengan metode ORB mencapai persentase 48\% dikenali benar dan 52\% salah dikenali, jadi dapat disimpulkan metode ORB berjalan cukup baik dalam mengenali ukiran.
\end{abstract}

Kata Kunci: Ukiran Bali, Pengenalan, ORB, Hamming Distance

\begin{abstract}
Balinese carving is one of the arts and culture in Bali and have various types in its application, but the lack of information resulted in people do not really know the kinds of Balinese carving. Lack of information about Balinese carvings can be solved by utilizing advances in information technology in image processing, which is to make application that can recognize Balinese carvings. Applications that made is a mobile application that can be used on smartphones with Android operating system. The method that applied is Oriented FAST and Rotated BRIEF (ORB) that able to recognize the image of Bali carving based on the features keypoints. Carved image matching using Bruteforce Hamming Distance to find the similarity between features carved images so that they can be identified. The results of the accuracy of the research process recognition Balinese carving method ORB reaches the percentage of $48 \%$ Balinese carvings recognizable and $52 \%$ did not recognize, so it can be concluded the result method ORB is quite good to recognize Balinese carving.
\end{abstract}

Keywords: Balinese Carving, Recognize, ORB, Hamming Distance

\section{Pendahuluan}

Ukiran Bali merupakan salah satu seni budaya yang ada di Bali. Ragam hias ukiran Bali memiliki banyak motif ataupun jenis dalam penerapannya pada arsitektur tradisional maupun bangunan di Bali, namun seiring perkembangannya banyak masyarakat kurang mengetahui atau memahami jenis ukiran Bali.

Ukiran Bali kurang diketahui oleh masyarakat disebabkan karena minimnya informasi tentang ukiran Bali. Informasi yang minim mengenai ukiran Bali dapat diatasi dengan memanfaatkan kemajuan teknologi informasi dibidang pengolahan citra, yakni untuk membangun aplikasi yang mampu mengenali ukiran Bali. Aplikasi yang dibangun merupakan aplikasi mobile yang dapat digunakan pada smartphone dengan sistem operasi Android. Aplikasi yang dimaksud yakni aplikasi pengenalan Ukiran Bali berbasis Android. Aplikasi pengenalan ini dibuat untuk membantu pengguna untuk dapat mengenali ukiran Bali sekaligus untuk melestarikan budaya Bali. 
Metode yang digunakan dalam penelitian ini menggunaka metode ORB. Metode ORB (Oriented FAST and Rotated BRIEF) merupakan metode pengenalan berbasis fitur berdasarkan keypoint, metode ini bersifat scale invariant dan rotation invariant dan juga lebih tahan terhadap noise [1]. Metode ORB dalam beberapa penelitian merupakan metode yang banyak digunakan dikarenakan kemampuannya dalam proses pengenalan dan pencocokan.

Beberapa penelitian yang menggunakan metode ORB yakni Implementation Of High Performance Feature Extraction Method Using Oriented Fast And Rotated Brief Algorithm oleh Prashant Aglave [2], penelitian dengan judul Performance Analysis of Various Feature Detector and Descriptor for Real-Time Video based Face Tracking [3] dan penelitian dengan judul "Fast Scene Matching Navigation Algorithm Based on ORB [4].

Aplikasi pengenalan Ukiran Bali dirancang dan dibangun dengan beberapa kelebihan dibanding penelitian-penelilitian sebelumnya. Kelebihan atau keunggulan yang dimaksud yakni aplikasi ini bersifat mobile sehingga penggunaannya lebih portable karena bisa digunakan pada smartphone Android, serta diimplementasikan untuk dapat melestarikan budaya Bali dengan cara mengenali serta memberi informasi ukiran Bali secara langsung.

\section{Metodologi Penelitian}

\subsection{Sumber Data}

Data sample ukiran Bali yang digunakan dalam penelitian diperoleh dengan cara pengambilan secara langsung menggunakan kamera. Sumber data lain diperoleh melalui studi kepustakaan pada beberapa karya ilmiah, tugas akhir, serta sumber-sumber pengolahan citra maupun computer vision. Sumber data yang digunakan sebagai citra referensi yakni Ukiran Kekarangan 15 buah, Ukiran Keketusan 3 buah dan Ukiran Patra 2 buah. Sumber data diambil dengan kamera smartphone dengan resolusi 13 MP.Citra referensi diambil berdasarkan teoriteori ukiran yang ada.

\subsection{Gambaran Umum}

Gambaran umum merupakan gambaran keseluruhan proses yang dilakukan sistem serta modul-modul yang digunakan untuk mengerjaan masing-masing proses tersebut yang diterapkan dalam pembuatan aplikasi.

Aplikasi ini dirancang sederhana sehingga pengguna awampun dengan mudah dapat menngunakan. Secara umum cara kerja aplikasi seperti pada Gambar 2.

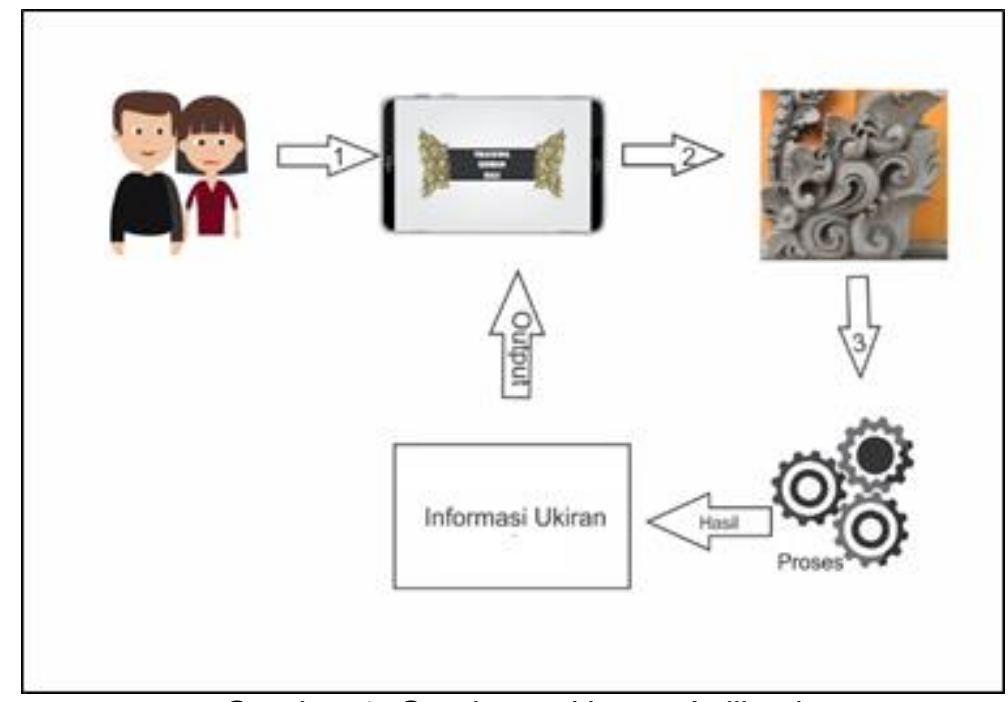

Gambar 1. Gambaran Umum Aplikasi

Gambaran umum aplikasi pada gambar 1 menjelaskan proses penggunaan aplikasi secara umum. Pengguna membuka aplikasi, kemudian pengguna mengarahkan aplikasi keobjek ukiran yang mau dikenali. Aplikasi memproses citra yang diterima dan memberikan output berupa informasi ukiran. 


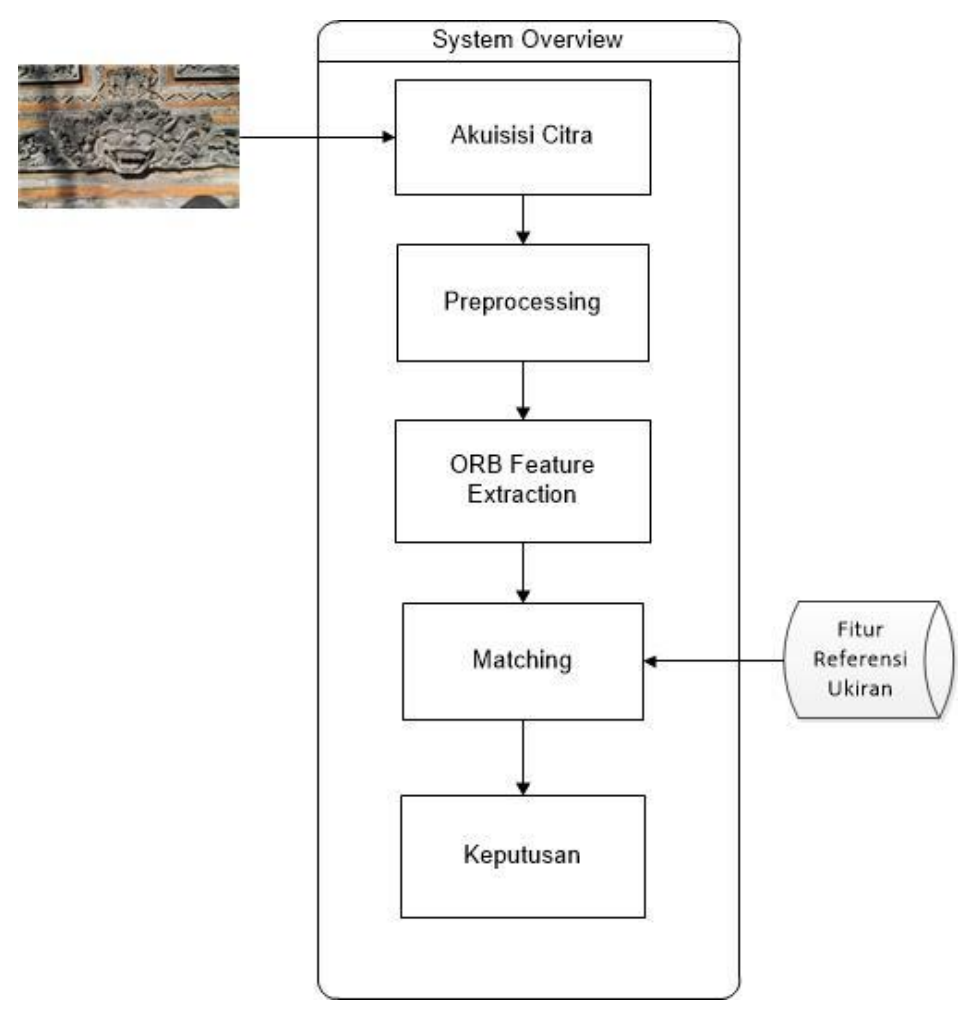

Gambar 2. Gambaran Umum Sistem

Tahap akuisisi citra merupakan tahapan untuk menerima input citra dengan langsung mengarahkan kamera smartphone ke objek citra ukiran.Tahapan preprocessing yaitu mengubah citra berdasarkan hasil akuisisi citra dan dikonversi menjadi citra keabuan.Tahapan ekstrasi fitur merupakan proses penerapan algoritma ORB dengan menggunakan bantuan library OpenCV dengan metode ORB Feature Detection dan Descriptor Exctractor. Tahap pencocokan merupakan proses antara citra uji dengan citra referensi. Pencocokan dilakukan dengan menghitung jarak antar nilai ekstrasi fitur ORB Descriptor antara citra uji dengan citra referensi. Metode penghitungan jarak untuk pencocokan menggunakan metode Brute-Force Hamming Distance.Tahap keputusan merupakan tahap pengambilan keputusan dari aplikasi. Keputusan diambil berdasarkan jumlah scene corners yang didapat. Apabila scene corners jumlahnya kurang dari 4 maka ukiran dianggap tidak terdeteksi. Apabila lebih dari 4 maka ditampilkan informasi mengenai ukiran.

\section{Kajian Pustaka}

\subsection{ORB}

ORB merupakan dekskriptor binary yang sangat cepat berbasis BRIEF. ORB memiliki sifat rotasi invariant dan tahan tehadap noise. Peforma ORB menghasilkan efisiensi 2 kali lipat dibandingkan SIFT diberbagai situasi. Algoritma ORB merupakan kombinasi dari dua teknik yang populer yaitu, FAST (Features for Accelerated Segment Test) dan BRIEF (Binary Robust Independent Elementary Features) untuk deskriptor keypoint [1].

ORB menggunakan intensitas orientasi centroid dalam penerapannya.Penerapan berdasarkan orientasi intensity centroid efektif dari sudut orientasi dari intensitas centroid. Intensitas centroid mengasumsikan bahwa intensitas sudut yang terkoreksi dari pusat, dan vektor ini dapat digunakan untuk menghubungkan orientasi [1]. Rosin mendefinisikan momen patch sebagai berikut:

$$
m_{p q}=\sum_{x y} x^{p} y^{q} I(x, y)
$$


Rumus Moment yang digunakan untuk menemukan centroid dengan adalah sebagai berikut:

$$
C=\left(\frac{m_{10}}{m_{00}}, \frac{m_{01}}{m_{00}}\right)
$$

Vektor dapat dibangun dari pusat sudut, $O$, ke centroid, $O C$. Rumus sederhana orientasi dari patch menjadi sebagai berikut:

$$
\theta=\operatorname{atan} 2\left(m_{01}, m_{10}\right)
$$

ORB menggunakan deskriptor BRIEF yang berfungsi untuk melakukan deskripsi terhadap bit string dari berbagai patch citra yang dibangun dari setiap set intensity tes binari dengan mempertimbangkan citra patch yang diperhalus. Binari tes $I$ dapat dirumuskan sebagai berikut [3]:

$$
\tau(p ; x, y):=f(x)=\left\{\begin{array}{ll}
1, & p(x)<p(y) \\
0, & p(x) \geq p(y)
\end{array}\right\}
$$

$p(x)$ adalah intensitas dari $p$ pada saat berada di titik $x$. Fitur $f$ digambarkan sebagai vektor dari binari tes $n$ sebagai berikut :

$$
f_{n}(p):=\sum_{1 \operatorname{sisn}} 2^{i-1} \tau(p ; x, y)
$$

\subsection{Brute-Force Hamming}

Pencocokan Brute-Force pada deskriptor (ekstraksi fitur) ORB menggunakan parameter perhitungan jarak Hamming dalam melakukan pencocokannya. Jarak Hamming digunakan untuk menunjukkan perbedaan antara dua string biner. Jarak Hamming dapat dihitung antara dua string biner dengan panjang yang sama. String biner kemudian dibandingkan dua bit pertama dalam setiap string. Hasil perbandingan apabila nilainya sama maka akan menghasilkan nilai "0", sedangkan jika keduanya berbeda, maka menghasilkan nilai "1". Langkah terakhir adalah menjumlahkan semua nilai biner dari hasil tersebut untuk menentukan kemiripan[5].

\subsection{Ukiran Bali}

Ukiran Bali merupakan salah satu seni budaya yang ada di Bali. Sebagai salah satu karya seni, ornament Ukiran Bali sering ditemui digunakan pada arsitektur bangunan tradisional Bali, alat musik tradisional Bali, maupun tempat suci, untuk menambah kesan artistik. Terdapat beberapa motif ukiran di Bali yakni Keketusan, Pepatraan dan Kekarangan [.

\section{Hasil dan Pembahasan}

\subsection{Hasil Pengenalan Ukiran}

Pengenalan ukiran berfungsi untuk menentukan informasi ukiran yang dikenali. Aplikasi pengenalan ukiran ini menggunakan 20 citra referensi ukiran sebagai acuan aplikasi dalam mengenali ukiran.

Citra uji ukiran yang digunakan berjumlah 25 ukiran Bali seperti yang ada pada Tabel 1. Setiap ukiran memiliki bentuk yang agak berbeda walaupun dengan jenis yang sama. Citra uji merupakan citra yang tidak tersimpan pada aplikasi.

Tabel 1. Uji Coba Pengujian

\begin{tabular}{|l|l|l|c|c|c|}
\hline No & Jenis Ukiran & Jumlah & Dikenali & $\begin{array}{c}\text { Dikenali } \\
\text { Benar }\end{array}$ & $\begin{array}{c}\text { Dikenali } \\
\text { Salah }\end{array}$ \\
\hline 1 & Kekarangan & 15 & $\mathbf{1 5}$ & $\mathbf{9}$ & $\mathbf{6}$ \\
\hline 2 & Pepatran & 5 & $\mathbf{5}$ & 2 & $\mathbf{3}$ \\
\hline 3 & Keketusan & 5 & $\mathbf{5}$ & $\mathbf{1}$ & 4 \\
\hline \multirow{2}{*}{ Total } & Ukiran Dikenali & $\mathbf{2 5}$ & $\mathbf{1 0 0 \%}$ \\
\cline { 3 - 6 } & Dikenali Benar & $\mathbf{1 2}$ & $\mathbf{4 8 \%}$ \\
\cline { 3 - 6 } & Dikenali Salah & $\mathbf{1 3}$ & $\mathbf{5 2 \%}$ \\
\hline
\end{tabular}

Hasil uji coba berdasarkan pada Tabel 1 ukiran yang berhasil dideteksi mencapai 100\%. Ukiran yang berhasil dideteksi mempunyai persentase dikenali benar yakni $48 \%$, dikenali salah52\% dan dikenali salah $0 \%$. Waktu dalam pengenalan yang tercepat yakni 3 detik dan 
terlama 15 detik. Jarak ukur pengenalan minimal yakni $20 \mathrm{~cm}$ dan terjauh yakni $40 \mathrm{~cm}$. Perbedaan waktu dan jarak ukur disebabkan bentuk ukiran yang berbeda-beda sesuai bentuk bangunan sehingga perlu dilakukan penyesuaian dalam mengenali.

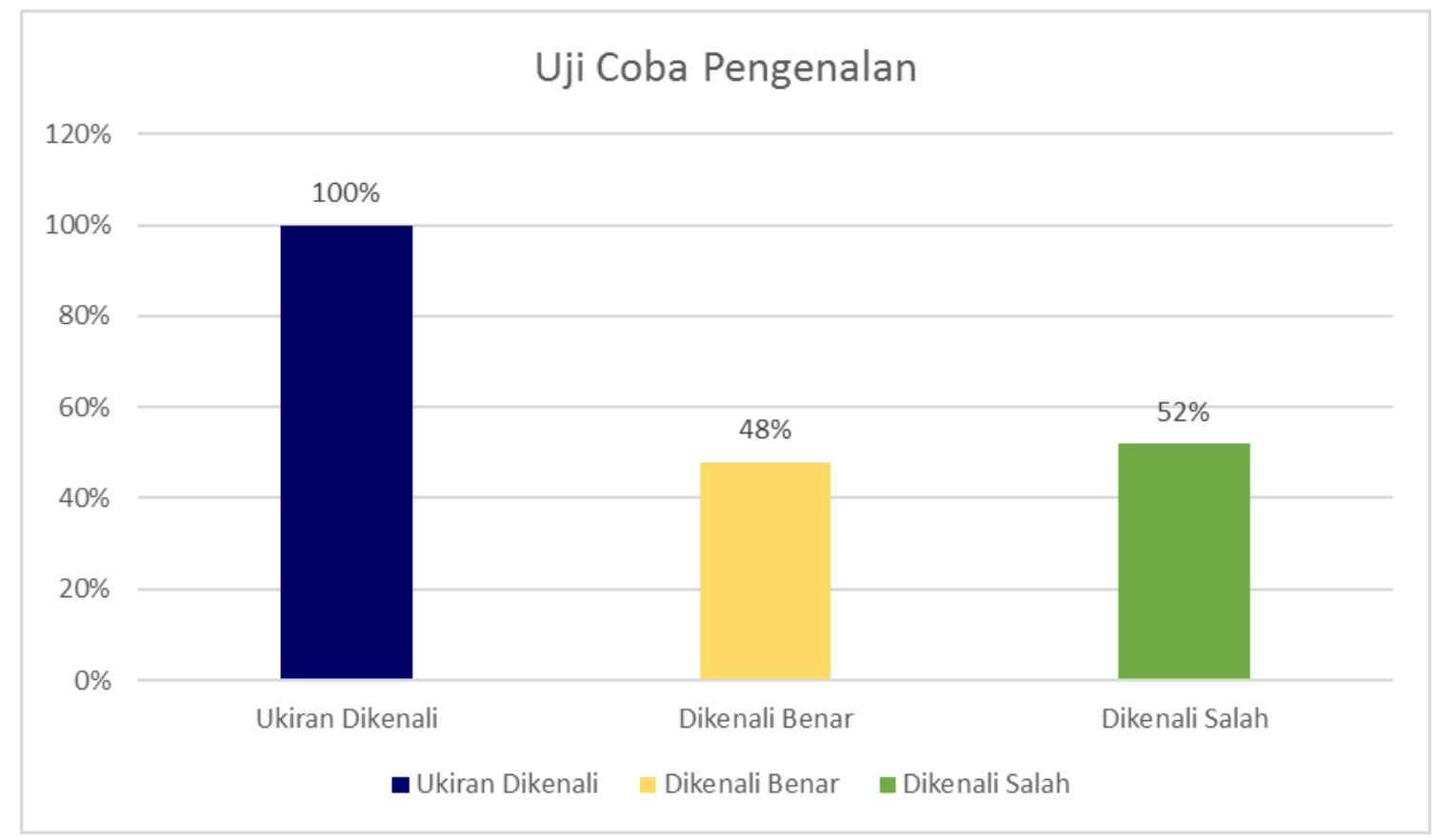

Gambar 3.Uji Coba Pengenalan

Hasil uji coba pengenalan berdasarkan pada Gambar 4 menunjukkan rasio aplikasi masih rendah yakni $48 \%$ citra yang dikenali, sedangkan yang dikenali salah $52 \%$. Persentase dikenali benar rendah disebabkan citra referensi yang tersimpan tidak memiliki nilai pencocokan deskriptor(hasil ekstrasi metode ORB) yang cukup. Nilai hasil pencocokan berdasarkan deskriptor sangat penting untuk menentukan kemiripan sehingga ukiran bisa dideteksi. Metode pencocokan Bruteforce Hamming distance semakin besar nilainya maka semakin tidak mirip.

\subsection{Tampilan pengujian Aplikasi.}

Uji coba dilakukan dengan menggunakan kamera smartphone Android dengan resolusi $1280 \times 576$ pixel, dengan cara mengarahkan kamera aplikasi langsung ke objek ukiran. Berikut ditampilkan contoh gambar hasil dari pengujian aplikasi.

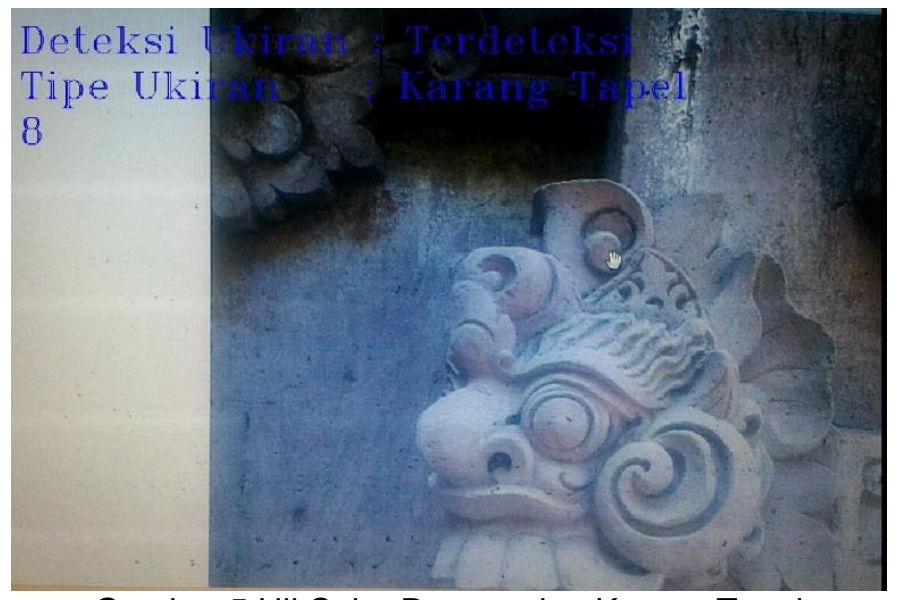

Gambar 5.Uji Coba Pengenalan Karang Tapel 
Tampilan hasil pengenalan dengan objek ukiran jenis Kekarangan Tapel. Hasil pengujian pengenalan pada Gambar 5 menampilkan informasi ukiran yang terdeteksi di bagian pojok kiri atas.

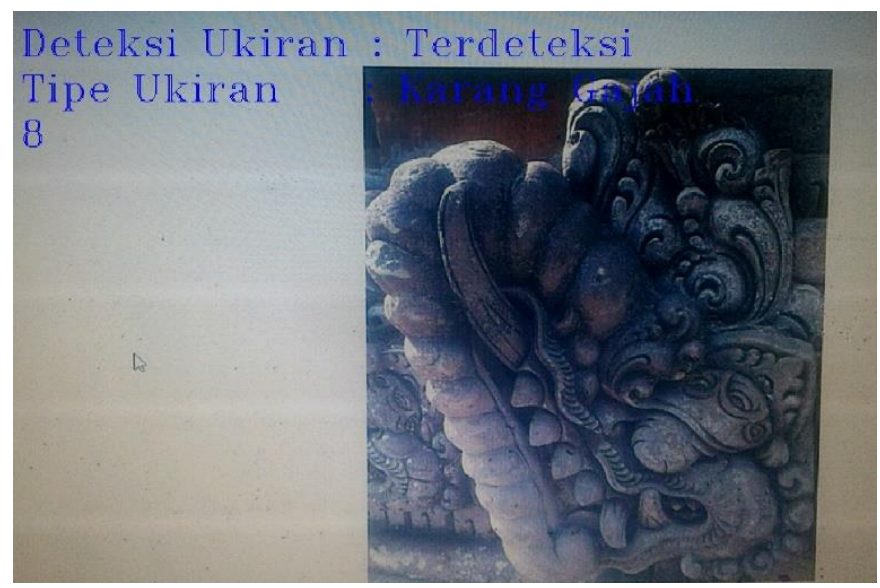

Gambar 6.Uji Coba Pengenalan Karang Gajah

Tampilan hasil pengenalan dengan objek ukiran tipe Kekarangan Tapel. Hasil pengujian pengenalan pada Gambar 6 menampilkan informasi ukiran yang terdeteksi di bagian pojok kiri atas.

\section{Kesimpulan}

Metode Oriented FAST and Rotated BRIEF dalam penerapannya pada aplikasi Pengenalan Ukiran Bali memperoleh akurasi pengenalan yang cukup baik yakni $48 \%$ dan $52 \%$ ukiran yang gagal dikenali. Keberhasilan pengenalan informasi dipengaruhi oleh beberapa faktor seperti, kualitas citra referensi, pencahayaan maupun jarak dalam melakukan pengenalan.

\section{Daftar Pustaka}

[1] Ethan R, Vincent R, Kurt K, "ORB: an efficient alternative to SIFT or SURF", ICCV. 2011, 2564-2571.

[2] Prashant A, Vijaykumar S K, "Implementation Of High Performance Feature Extraction Method Using Oriented Fast And Rotated Brief Algorithm", International Journal of Research in Engineering and Technology. 2015; 5 : 394-397.

[3] Akash P, D.R. Kasat, Sanjeev J, V M Thakare,"Performance Analysis of Various Feature Detector and Descriptor for Real-Time Video based Face Tracking", International Journal of Computer Applications.2014; 93 :37-41.

[4] Chao H, Weidong Z, "Fast Scene Matching Navigation Algorithm Based on ORB", Journal of Information \& Computational Science, 2014; 11: 3857-3863.

[5] I Wayan Agus Suryawibawa, I Ketut Gede Darma Putra, Ni Kadek Ayu Wirdiani,"Herbs Recognition Based on Android using OpenCV", IJIGSP.2015; 7:1-7.

[6] http://repo.isi-dps.ac.id/id/eprint/137, diakses tanggal 4 Oktober 2015 